DOI 10.37882/2223-2974.2021.01.22

\title{
РИСК ОРИЕНТИРОВАННЫЙ ПОДХОД ДЛЯ ОБЕСПЕЧЕНИЯ ПРОМЫШЛЕННОЙ БЕЗОПАСНОСТИ НА ПРЕДПРИЯТИЯХ ТОПЛИВНО-ЭНЕРГИТИЧЕСКОГО КОМПЛЕКСА
}

\section{THE RISK BASED APPROACH TO ENSURE INDUSTRIAL SAFETY AT THE ENTERPRISES OF THE TOP-LIVNO- ENERGY COMPLEX}

\section{N. Skvortsova \\ L. Filimonova \\ K. Andronova}

Summary: Industrial safety of an object involves ensuring such a state of protection of this object from various types of threats, which creates conditions for its normal functioning and compliance with the established modes. The article presents a variant of the algorithm for step-by-step analysis of the causes of accidents at the enterprise. This algorithm includes identification of direct and indirect factors that determine the direction and intensity of emergencies at the enterprise using a system of organizational and technical methods (risk sessions) aimed at timely identification, assessment and prevention of hazards. We consider the classical problem of hazard identification based on methods (risk sessions) in a matrix format with an estimated utility function, with subsequent decision-making based on the identification results. The author offers justifications, conclusions and recommendations regarding the development and launch of measures to improve the efficiency and reliability of industrial safety systems at the hazardous production facility of JSC "MES-soyakhaneftegaz". The principal distinctive feature of the research results is the scheme of manipulations in the assessment of cause-and-effect relationships that determine the intensity and direction of factors of direct and indirect impact on the occurrence of emergency situations at the enterprise, which allows us to justify the choice of a management solution to the corresponding challenge to the industrial safety system of a particular object in the sphere of its production activities. Factors of potential reliability and safety for the environment are also identified. Effective risk management is achieved on the basis of a clear understanding of the areas and zones of identified risks, the probability of their occurrence and the scale of consequences of risk events.

Keywords: hazard identification, industrial safety system, risk management, functionality, risk management, risk minimization.
$\mathrm{H}$ а сегодняшний день предприятия воспринимаются инвесторами не только с позиции удовлетворения потребностей общества в тех или иных товарах. Но, в большей степени, с точки зрения объекта инвестирования и перед Топ-менеджерами ставятся задачи в части обогащения частного капитала без учета
Скворцова Надежда Константиновна

Д.э.н., профессор, Тюменский индустриальный университет

skvortsovank@tyuiu.ru

Филимонова Лариса Акрамовна К.э.н., дочент, Тюменский индустриальный университет filimonovala@tyuiu.ru

Андронова Ксения Алексеевна Тюменский индустриальный университет Kseniandronova@yandex.ru

Аннотация: Промышленная безопасность объекта предполагает обеспечение такого состояния защищенности этого объекта от разного рода угроз, при котором создаются условия для его нормального функционирования и выполнения установленных режимов. В статье представлен вариант алгоритма поэтапного анализа причин проявления аварийных ситуаций на предприятии. Данный алгоритм включает идентификацию прямых и косвенных факторов, определяющих направление и интенсивность возникновения аварийных ситуаций на предприятии с использованием системы организационно-технических методов (риск-сессий), направленных на своевременное выявление, оценку и предупреждение опасностей. Рассматривается классическая задача идентификации опасностей на основе методов (риск-сессий) в матричном формате с оценочной функцией полезности, с последующим принятием решений по результатам идентификации. Предложены обоснования, заключения и рекомендации в части разработки и запуска мероприятий по повышению эффективности и надежности систем промышленной безопасности на опасном производственном объекте А0 «Мессояханефтегаз». Принципиальной отличительной особенностью результатов исследования являются схемы манипуляций в оценке причинно-следственных связей, определяющих интенсивность и направленность факторов прямого и косвенного воздействия на возникновение аварийных ситуаций на предприятии, что позволяет обосновать выбор варианта управленческого решения на соответствующий вызов системы промышленной безопасности конкретного объекта в сфере осуществляемой им производственной деятельности.

Ключевые слова: идентификация опасностей, система обеспечения промышленной безопасности, риск-сессии, функциональность, управление рисками, минимизация рисков.

территориальных особенностей размещения предприятия и возможных техногенных рисков, связанных с производственной сферой деятельности. Особую актуальность в современных условиях потеряли мероприятия по снижению техногенных рисков в силу падения деловой и потребительской активности рынков. Не толь- 
ко малый и средний, но и крупный бизнес столкнулся с потерей ликвидности, контрактов и заказов. Проблемы усугубляются старением производственных мощностей в условиях ограниченности свободных средств и неопределенности экономической ситуации не только в нашей стране, но и в мировой практике. И, не смотря на появление государственных прямых и косвенных источников финансирования для осуществления операционной деятельности предприятий, сложно рассчитывать на запуск современных мероприятий по обеспечению собственной техносферной безопасности. Инвестор еще долго будет восстанавливаться от вынужденного простоя, обусловленного пандемией. А как следствие возврат к достигнутым ранее уровням деловой и инвестиционной активности предприятий произойдет не в скором времени. Для наращивания производственного, интеллектуального и инновационного потенциалов предприятиям необходима социальная стабильность и достойный уровень качества жизни. Отсюда получаем замкнутый круг, для того чтобы предприятию выйти на заданные объемы промышленного производства необходимо оздоровление потребительского рынка, для которого, в свою очередь необходимы стабильные источники денежных доходов, которые предприятие не имеет возможности обеспечить своим работникам. В результате, как худший вариант разрыва замкнутого круга является снижение затрат на производство продукции. Наиболее простыми способами снижения издержек с позиции инвестора следует признать либерализацию принципов экологической и техносферной безопасности производственных процессов. Примером данному варианту служит промышленный прорыв Китая в 90-х 00- x годах, в результате которого прилегающая территория к промышленным зонам стала не пригодна для качественного уровня жизни населения. При этом промышленная революция китайского варианта прорыва привела к технологическому прорыву в 2010-2020 годам нынешнего столетия. Вредные и опасные производства китайский инвестор переводит в Африку, Индию, Мексику и Россию. Следовательно, Ростехнадзору и Роспотребнадзору совместно с обществом предстоит в ближайшие годы усилить внимание за отечественным бизнесом, особенно который входит в группу техногенных рисков с высокой долей вероятности аварий. В условиях нестабильной и быстро меняющейся среды особую актуальность приобретает умение менеджеров предприятий и органов исполнительной власти правильно оценивать в режиме реального времени потенциальную экологическую ситуацию в регионе и принимать качественные управленческие решения в целях минимизации техногенных рисков в регионе.

Применение широкого спектра научных подходов, методов и инструментов в идентифицировании прямых и косвенных факторов, определяющих направление и интенсивность возникновения аварийных ситуаций на предприятии, позволяет обосновать реновационные программы применительно к стратегическим и инвестиционным планам развития отечественной промышленности и российских городов. Классические эвристические методы и статистический инструментарий (наблюдения, выборки, опрос), которые заслужили доверие линейных руководителей при мониторинге производственных и технологических прессов, описаны в трудах многих авторов [1-7]. На уровне крупных компаний применяются методы синергетики (теория совместных действий) или методы нелинейной динамики $[8,9,10]$. Yu.A. Izvekov, E.M. Gugina, V.V. Shemetova обpaщают внимание на следующие особенности: «Nonlinear dynamics can be very useful for evaluation of the personnel opportunities range in the analysis and prevention of technogenic risks» [8].

Авторы статьи предлагают остановиться на специфических методах и подходах применительно к особенностям поднятой проблемы настоящего исследования. На сегодняшний день наибольшую признательность получили следующие современные методы (риск-сессий) идентификации опасностей в HSE. Одним из которых является Hazard and operability study (HAZOP) [11, 12, 13]. Это исследование опасности и работоспособности, выполняемое командой экспертов и заключающееся в идентификации проблем опасности функционирования системы.

Данное исследование направлено на идентификацию возможных отклонений в технологическом процессе, используемом на предприятии, установления их возможных причин и оценки последствий.

Причины, провоцирующие негативные явления при эксплуатации опасных производственных объектов (ОПО), можно классифицировать по двум направлениям: технические и организационные [15]. Технические причины - это дефекты и повреждения конструкций зданий ОПО, технические проблемы с оборудованием; повышенный износ оборудования; низкий уровень оснащения производства автоматическими системами; отсутствие средств сигнализации и оперативной связи и т.д.

Организационные причины возникновения аварий это низкий уровень производственно-технологической дисциплины на ОПО; недостаточная квалификация персонала; недооценка возможного риска на конкретном рабочем месте; низкая организация производства работ [16].

Кроме того, на ОПО нефтегазовых предприятий довольно часто нарушается технологический процесс, оборудование находится в ненадлежащем для эксплуатации состоянии и игнорируются нормативы безопасности [17]. 
Анализ производственных аварий показывает, что большинство из них происходит из-за повторяющихся ошибок. При этом многочисленные проблемы могли быть легко обнаружены в ходе систематической оценки рисков, которая должна охватывать весь жизненный цикл от разработки концепции до демонтажа.

Идентификации опасностей на основе методов (рисксессий) призваны обеспечить получение ответов на вопросы: что плохого может произойти? (Идентификация опасностей); как часто это может случаться? (Анализ частоты); какие могут быть последствия? (Анализ последствий).

Порядок анализа риска включает ряд этапов: планирование работ; организация работ; формирование информационного потока; идентификация опасностей; оценка риска аварии на ОПО; определение степени опасности аварий на ОПО; разработка и корректировка мероприятий, направленных на снижение риска аварий.

Свод особенностей применения и функционального назначения методов идентификации опасностей представлен в обзоре [18].

HASID - исследование по идентификации опасностей (Hazard Identification Studies) заключается в проведении сессий по принципу «мозгового штурма- наиболее эффективного способа, основанного на установленном процессе или этапе» группой экспертов, имеющее целью выявить потенциальные опасности, сопряженные с реализацией крупного проекта [16].

Преимущества метода заключаются в обнаружении опасных факторов уже на начальной стадии проекта; фиксация опасных факторов и их устранение, снижение или их указание во время проектирования; оценка причин и последствий при реализации опасного фактора; прохождение проверки рекомендуемых мероприятий со стороны руководства и контролирующих органов; исключение задержки получения проектов и строительства, а также перерасхода бюджета.

PHISER - исследование, связанное с охраной труда (ОТ), промышленной безопасностью и охраной окружающей среды, (Project HSE review) представляет собой структурированный обзор вопросов по профилю промышленной, экологической безопасности (ПЭБ), ОТ, гражданской защиты (ГЗ), является основным инструментом управления рисками в области ПЭБ и ОТ применительно к каждому этапу жизненного цикла крупного объекта. В рамках обзора PHISER проверяются планы и мероприятия по ПЭБ, ОТ и ГЗ, относящиеся к конкретному крупному проекту, результат PHISER позволяет принять решение о переводе капитальных проектов (КП) на следующий этап.
HAZOP $[9,11,12,13,18]$ - систематический и всесторонний анализ технологических рисков (HAZard) и функциональности оборудования (OPerability), признанный в мировой практике системный подход к определению источников отказов (конструктивных и процедурных). Данная сессия характеризуется следующим: привязана к процедуре работы по КП: использует навыки мультидисциплинарной команды, работающей сообща по заданной методологии; оценивает достаточность предусмотренных мер защиты технологической системы; определяет работоспособность оборудования. А также HAZOP - это уже хорошо описанный и зарекомендовавший себя метод, который применим в течение всего жизненного цикла актива, очень эффективен при проектировании технологических систем. С помощью HAZOP выявляются отклонения от технологических параметров и их последствия. Задачами процесса HAZOP являются: организация анализа опасностей и работоспособности технических и технологических решений проектной документации проекта на этапе «определение»; обеспечение полного анализа рисков и обоснование необходимого уровня безопасности; обоснование необходимого уровня безопасности и проектирования системы противоаварийной защиты (СПАЗ); мониторинг выполнения мероприятий по снижению рисков.

Таким образом, применение методики риск-сессий позволяет оценить проектные решения с точки зрения опасностей, возникновение которых возможно по причинам различных отклонений; установить причины их возникновения; оценить последствия опасностей; определить средства защиты и оценить достаточность этих средств; выработать рекомендации по сокращению последствий выявленных проблем, что подчеркивает актуальность поднятой авторами проблемы выбора метода и инструментов диагностики и профилактики техногенных рисков.

Мы рассмотрим, что представляет собой краткий обзор основных концепций традиционного подхода к анализу рисков, который включает алгоритм осуществления анализа: определение систем для анализа; выявление опасностей; оценка возможности предотвращения; анализ последствий; результаты анализа риска; разработка рекомендаций по уменьшению риска. В процессе выполнения анализа рисков, сценарий развития представляет собой цепочку событий, которые могут привести к нежелательному исходу. Приведем порядок событий анализа сценария:

разгерметизация; обнаружение; изоляция; смягчение воздействия.

За основу был взят анализ опасностей с помощью методов риск-сессий идентификации опасностей на ОПО нефтегазодобывающего комплекса, в результате которого были рассмотрены наиболее высокие риски при 
технологическом процессе сбора и подготовки нефти предприятия.

Результатом проведения такой аналитической работы является фиксация опасных факторов и их снижение (по возможности - устранение), выявление как можно большего количества вероятных рисков аварийных ситуаций. Согласно информации Ростехнадзора причиной многочисленных аварий, а именно 60\% в нефтегазовой промышленности России, является низкий уровень организации работ. При этом три наиболее значительных фактора, влияющих на возникновение аварий - это человеческий фактор, технологический фактор, отсутствие систем аварийной защиты, а также недостаток внимания руководителей предприятий к вопросам промышленной безопасности и охраны труда. Об этом свидетельствует тот факт, что коэффициент смертельного травматизма в дочерних подразделениях, таких как, ООО «Газпром переработка», ООО «Газпром переработка - Сургут», ООО «Газпром переработка - Уренгой», ООО «Газпром Тюмень», АО «Мессояханефтегаз» выше, чем в основном производстве ОАО «Газпром». Для снижения количества аварийных ситуаций и необходимы анализ причин аварийных ситуаций и внедрение методов идентификации опасностей на предприятии.

Ведущие нефтедобывающие компании накопили опыт внедрения современного подхода к вопросам управления ПЭБ, ОТ и ГЗ на основе методов риск-сессий. Исследование, которое послужило фундаментом настоящей публикации, проводилось на базе промыслового объекта АО «Мессояханефтегаз». Авторами применен синтез статистического инструментария и современных методов (риск-сессий) идентификации опасностей на ОПО заказчика. Цель проведения риск-сессии идентификации опасностей на центральном пункте сбора (ЦПС): обнаружение опасных факторов при эксплуатации ЦПС; фиксация опасных факторов и их устранение, снижение или их указание; определить, как можно больше вероятных рисков и сценариев и далее ранжировать их по воздействию и вероятности для дальнейшего анализа и снижения воздействия; проведение рекомендуемых мероприятий по улучшению.

Обзор в соответствии с техническим заданием на проведение анализа риск-сессий НAZOP проводился в отношении позиций: осмотр территории ЦПС; обустройство переходов через линии трубопроводов; системы оповещения о пожаре; состояние эвакуационных путей; анализ инструкций по безопасной эксплуатации объекта; контроль резервного источника электропитания; рассмотрение сценария возможного возгорания дизельной электростанции при автоматическом включении ее в работу.

Результаты проверки: проведен осмотр трубопро- водов по сбору сырой нефти; рассмотрены результаты проведенных ранее риск-сессий; проведен осмотр резервной электростанции; проанализированы риски при перегрузке генератора; рассмотрен возможный сценарий возгорания дизельной электростанции; запланировано мероприятие по снижению возможности возникновения возгорания на станции (установить предохраняющее устройство, исключающее автоматический пуск электростанции до устранения короткого замыкания электрических сетей внутри ЦПС).

Площадка промыслового объекта расположена севернее Северного полярного круга. Технологический процесс AO «Мессояханефтегаз» заключается в подготовке и сборе нефти. Данные об опасных веществах в соответствии с Приложением 1 Федерального закона от 21 июля 1997 г. № 116-Ф3 «О промышленной безопасности опасных производственных объектов» представлены в табл.1

Пример обобщения сведений об опасных веществах приведен по нефти в таблице 2.

В таблицах 3 и 4 приведены данные о количествах опасных веществ, веществах, обращаемых на ОПО и их классе опасности.

Аварийные ситуации классифицируются в зависимости от количества людей, пострадавших в этих ситуациях, людей, у которых оказались, нарушены условия жизнедеятельности, размера материального ущерба, а также границы зон распространения поражающих факторов чрезвычайных ситуаций. В зависимости от объема и площади разлива нефти на местности выделяются чрезвычайные ситуации следующих категорий: локального значения, муниципального значения, территориального значения, регионального значения, федерального значения. Результатом аварий на объектах, использующих нефть, кроме потерь продукции, является токсическое поражение (загрязнение) окружающей среды.

Для установления последовательности событий, возникающих в результате аварий и разлива нефти и выброса газа, и их возможного сочетания, разработана схема причинно-следственных закономерностей развития аварий. Схема приведена на (рис.1).

По данным Ростехнадзора основными причинами аварий, происходящих на предприятиях добычи нефти и газа, являются нарушения требований промышленной и пожарной безопасности, неэффективное осуществление производственного контроля, использование неисправного оборудования, нарушение технологии производства работ. Опасности, связанные с проведением технологического процесса первичной подготовки и перекачки нефти, могут быть обусловлены авариями с 
Таблица 1.

Данные об опасных веществах на декларируемом объекте

\begin{tabular}{|c|c|c|c|c|}
\hline \multirow{2}{*}{$\begin{array}{c}\text { Составляющая (участок) } \\
\text { объекта }\end{array}$} & \multirow{2}{*}{$\begin{array}{c}\text { Наименование опасного } \\
\text { вещества }\end{array}$} & \multicolumn{3}{|c|}{ Количество опасного вещества, т } \\
\hline & & аппараты & трубопроводы & $\begin{array}{c}\text { наибольшая единица обо- } \\
\text { рудования }\end{array}$ \\
\hline \multirow[t]{6}{*}{ Технологическая площадка } & Нефть & 2052,01 & 1616,65 & 86,22 \\
\hline & Попутный нефтяной газ & 25,73 & 0,82 & 1,23 \\
\hline & Дизельное топливо & 35,22 & - & 17,0 \\
\hline & Масло минеральное & 0,28 & 0,17 & 0,14 \\
\hline & Ингибиторы & 64,64 & 3,35 & 3,84 \\
\hline & Деэмульгаторы & 29,79 & 2,01 & 31,825 \\
\hline Площадка резервуаров & Нефть & 34488 & - & 6897,6 \\
\hline \multirow[t]{6}{*}{ Всего } & Нефть & \multicolumn{3}{|c|}{38156,66} \\
\hline & Попутный нефтяной газ & \multicolumn{3}{|c|}{26,55} \\
\hline & Дизельное топливо & \multicolumn{3}{|c|}{35,22} \\
\hline & Масло минеральное & \multicolumn{3}{|c|}{0,45} \\
\hline & Ингибиторы & \multicolumn{3}{|c|}{67,99} \\
\hline & Деэмульгаторы & \multicolumn{3}{|c|}{31,80} \\
\hline
\end{tabular}

Характеристика опасного вещества - нефти

\begin{tabular}{|c|c|c|}
\hline № & Наименование параметра & Параметр \\
\hline 1 & 2 & 3 \\
\hline 1 & Название & нефть \\
\hline 2 & Вид & жидкость \\
\hline 3 & Химическая формула & - \\
\hline 4 & Состав & смесь углеводородов \\
\hline \multirow[t]{4}{*}{5} & Данные по взрывоопасности & легковоспламеняющаяся жидкость \\
\hline & Температура вспышки, оС & -20 \\
\hline & Температура самовоспламенения, оC & $223-375$ \\
\hline & Пределы взрываемости, \% для газа (по метану) & $5-15$ \\
\hline 6 & $\begin{array}{l}\text { Токсическая опасность } \\
\text { ПДК в воздухе рабочей зоны, мг/м3 } \\
\text { ПДК в атмосферном воздухе, мг/м3 }\end{array}$ & $\begin{array}{l}3 \text { класс опасности } \\
10 \\
50 \text { (ОБУВ) }\end{array}$ \\
\hline 7 & Реакционная способность & при рабочей температуре химически интерна \\
\hline 8 & Запах & специфический \\
\hline 9 & Коррозионное воздействие & отсутствует \\
\hline 10 & Меры предосторожности & $\begin{array}{l}\text { устройство приточно-вытяжной вентиляция, обеспечение индивидуаль- } \\
\text { ными средствами защиты }\end{array}$ \\
\hline 11 & $\begin{array}{l}\text { Информация о воздействии на людей и окружающую среду, в том числе } \\
\text { от поражающих факторов при аварии }\end{array}$ & $\begin{array}{l}\text { при непосредственном контакте человека с нефтью возникают отравле- } \\
\text { ния, кожные поражения. Разливы нефти приводят к загрязнению земель } \\
\text { и атмосферного воздуха продуктами испарения. При возникновении по- } \\
\text { жаров происходит загрязнения атмосферного воздуха продуктами горе- } \\
\text { ния нефти. Люди могут пострадать от загазованности продуктами горе- } \\
\text { ния и термического воздействия }\end{array}$ \\
\hline 12 & Средства защиты & $\begin{array}{l}\text { сертифицированные средства индивидуальной и коллективной защиты } \\
\text { работников }\end{array}$ \\
\hline 13 & Способы перевода вещества в состояние не оказывающее вреда & механические, химические \\
\hline 14 & Меры первой помощи пострадавшим от воздействия вещества & $\begin{array}{l}\text { вынести из отравленной атмосферы. При тяжелых отравлениях - искус- } \\
\text { ственное дыхание. }\end{array}$ \\
\hline
\end{tabular}


Таблица 3.

Данные о количествах опасных веществ, на опасном производственном объекте

\begin{tabular}{|c|c|c|c|c|c|c|c|c|c|c|c|}
\hline \multirow[b]{3}{*}{$\begin{array}{c}\text { № } \\
\text { П/П }\end{array}$} & \multicolumn{2}{|c|}{ Вещество } & \multicolumn{9}{|c|}{ Признаки идентификации } \\
\hline & \multirow[b]{2}{*}{ 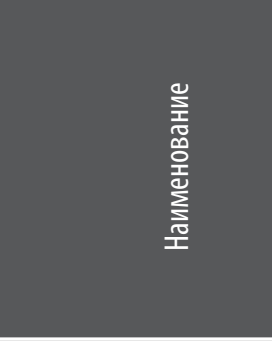 } & \multirow[b]{2}{*}{ 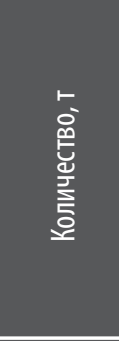 } & \multirow[b]{2}{*}{ 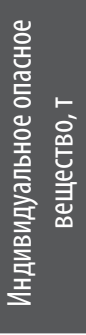 } & \multirow[b]{2}{*}{ 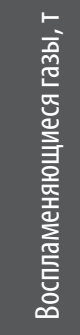 } & \multicolumn{2}{|c|}{ Горючие жидкости, т } & \multirow[b]{2}{*}{ 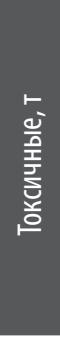 } & \multirow[b]{2}{*}{ 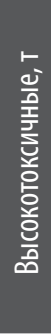 } & \multirow[b]{2}{*}{ 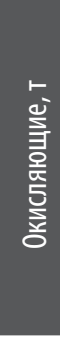 } & \multirow[b]{2}{*}{ 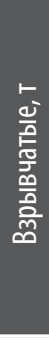 } & \multirow[b]{2}{*}{ 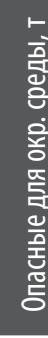 } \\
\hline & & & & & 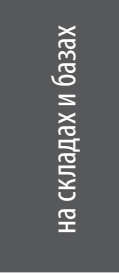 & 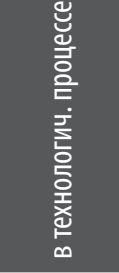 & & & & & \\
\hline 1 & 2 & 3 & 4 & 5 & 6 & 7 & 8 & 9 & 10 & 11 & 12 \\
\hline 1 & Нефть & 38156,66 & - & - & 34488,0 & 3668,6 & - & - & - & - & - \\
\hline 2 & Дизельное топливо & 35,22 & - & - & 35,22 & - & - & - & - & - & - \\
\hline 3 & Масло минеральное & 0,45 & - & - & - & 0,45 & - & - & - & - & - \\
\hline 4 & Попутный нефтяной газ & 26,55 & - & 26,55 & - & - & - & - & - & - & - \\
\hline 5 & Ингибиторы & 67,99 & - & - & 58,24 & 9,75 & - & - & - & - & - \\
\hline 6 & Деэмульгаторы & 31,80 & & - & 25,09 & 6,71 & & & & & \\
\hline \multicolumn{3}{|c|}{ Всего на декларируемом объекте, т } & - & 26,55 & 34606,55 & 3685,51 & - & - & - & - & - \\
\hline \multicolumn{3}{|c|}{ Предельное количество, т } & - & 200 & 50000 & 200 & 200 & 20 & 200 & 50 & 200 \\
\hline
\end{tabular}

Таблица 4.

Вещества, обращаемые на опасном производственном объекте, класс опасности веществ

\begin{tabular}{|c|c|c|c|c|}
\hline № & Вещество & Количество & Класс опасности & Характеристика \\
\hline 1 & 2 & 3 & 4 & 5 \\
\hline 1 & Нефть & 38156,66 & 3 - умеренно опасное & $\begin{array}{l}\text { По приведенной классификации нефть является нервным ядом, обладающим } \\
\text { наркотическим действием и поражающим, главным образом, центральную } \\
\text { нервную систему (ЦНС). Вызывает головокружение, сердцебиение, общую } \\
\text { слабость. При попадании на кожу вызывает кожные заболевания. }\end{array}$ \\
\hline 2 & Диз. топливо & 35,22 & 4 - малоопасное & $\begin{array}{l}\text { В мелкораспыленном состоянии оказывает раздражающее действие на } \\
\text { слизистые оболочки. Предельно допустимая концентрация в воздухе - 0,3 } \\
\text { мг/дм3. Систематический контакт с кожей вызывает кожные заболевания, } \\
\text { резкие боли и отеки. }\end{array}$ \\
\hline 3 & Масло минеральное & 0,45 & 3 - умеренно опасное & $\begin{array}{l}\text { Нефтяные масла представляют реальную угрозу для здоровья человека } \\
\text { (особенно в условиях, когда возможно образование масляного тумана). При } \\
\text { наличии в маслах серы, могут возникать условия для выделения сероводоро- } \\
\text { да, вызывающего отравление с мгновенной потерей сознания. Воздействие } \\
\text { масел на кожу человека может вызвать экзему и воспаление кожных покро- } \\
\text { вов, злокачественные опухоли, фолликулиты и т.д. }\end{array}$ \\
\hline 4 & $\begin{array}{c}\text { Попутный нефтяной } \\
\text { газ }\end{array}$ & 26,55 & 4 - малоопасное & $\begin{array}{l}\text { Отравления нефтяным газом, являющимся сильным нервным ядом, могут } \\
\text { привести к поражению ЦНС, последствия чего иногда проявляются на про- } \\
\text { тяжении последующих нескольких лет. }\end{array}$ \\
\hline 5 & Ингибиторы & 67,99 & 3 - умеренно опасное & $\begin{array}{l}\text { Канцерогенным действием не обладают. Однократное воздействие на кожу } \\
\text { опасности не представляет; при многократном воздействии возможно раз- } \\
\text { витие дерматита. Не проникают через неповрежденную кожу. При попадании } \\
\text { в глаза вызывают химический ожог 2 - 3-й степени, который проходит без } \\
\text { лечения через } 2 \text { - } 3 \text { недели. Обладают аллергическими свойствами. }\end{array}$ \\
\hline 6 & Деэмульгаторы & 31,80 & 3 - умеренно опасное & $\begin{array}{l}\text { Умеренно опасная по, степени воздействия на организм, продукция в соответ- } \\
\text { ствии с ГОСТ 12.1.007. Токсичн при вдыхании, проглатывании и попадании на } \\
\text { кожу. При проглатывании может вызвать слепоту. Легковоспламеняющаяся } \\
\text { жидкость. Загрязняет окружающую среду. }\end{array}$ \\
\hline
\end{tabular}




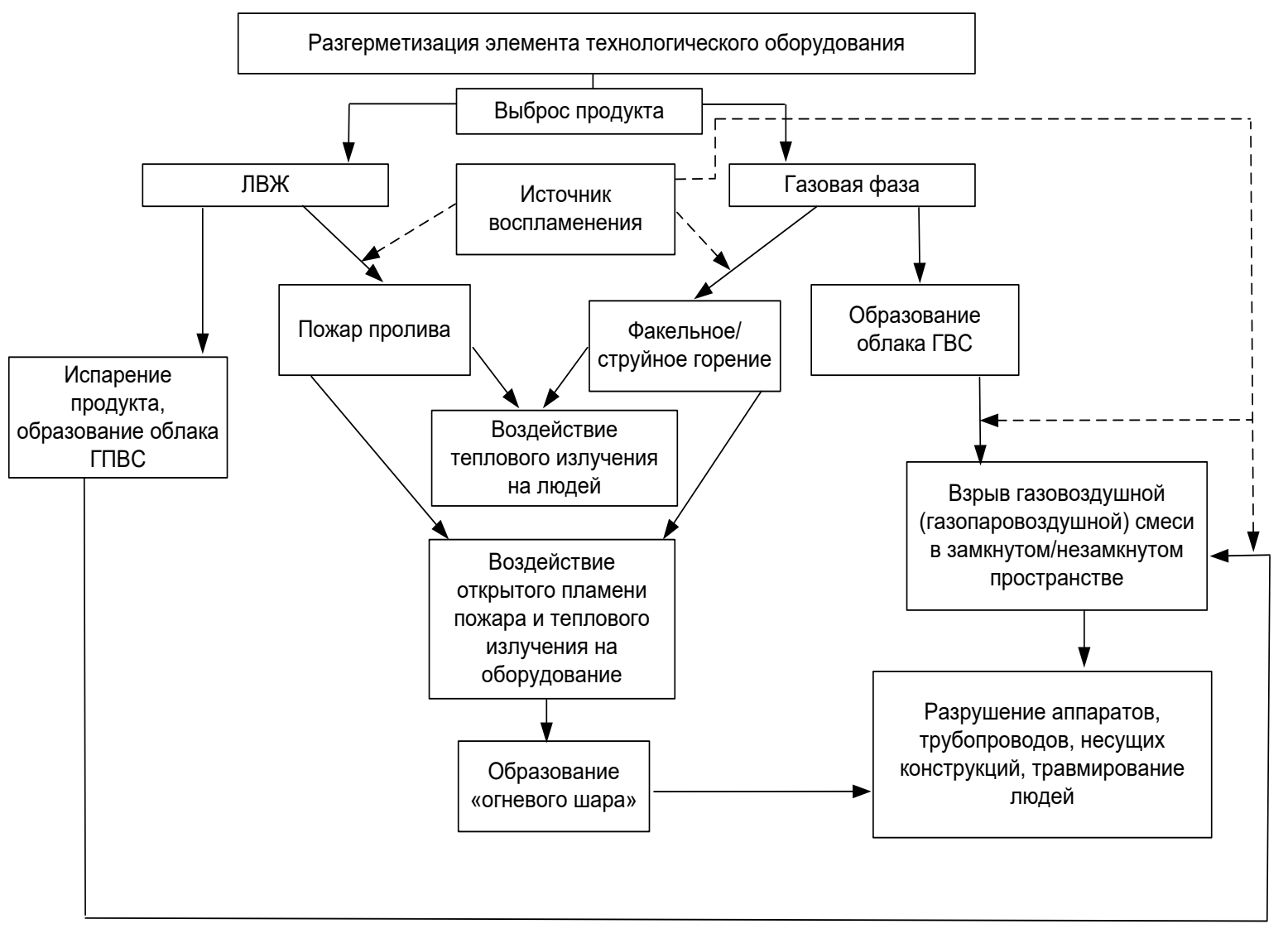

Рис. 1. Схема причинно-следственных закономерностей развития аварий.

оборудованием и трубопроводами.

Мониторингу были подвергнуты технологическая площадка и площадка резервуаров. По результатам исследования, проводимого авторами установлено, что основными причинами, способствующими возникновению аварий в $\mathrm{AO}$ «Мессояханефтегаз», являются техническое состояние оборудования и некачественная система предупреждения возникновения аварий и несчастных случаев. На территории АО содержатся опасные вещества, в связи с чем здесь возможны аварии, которые могут сопровождаться взрывами, пожарами и загрязнением территории. При этом наибольшее негативное воздействие, согласно изученным документам, связано с загрязнением нефтью окружающей среды и пожаром при воспламенении разлитой нефти. Также имеет место высокий уровень износа оборудования. Присутствуют факты несоблюдения правил техники безопасности. Зафиксированы факты возгорания оборудования, вызванные нарушением герметичности трубопроводов, отказом запорной арматуры и разъемных соединений и др. Перечень основных причин возникновения аварий представлен в таблице 5 .

Приведенные данные свидетельствуют о том, что на объектах, содержащих указанные вещества, возможны аварии, которые сопровождаются взрывами, пожарами и загрязнением территории.

Причины возникновения аварий и нарушений технологического процесса могут быть объединены в группы: разрушение (разгерметизация) технологического оборудования, трубопроводов и запорной арматуры и отказы систем противоаварийной защиты объекта; ошибки, запаздывание, бездействие персонала в штатных и нештатных ситуациях, несанкционированные действия персонала; внешние воздействия природного и техногенного характера.

Анализа причин позволяет выделить следующие типы аварий: С-1 - пролив опасного вещества, выброс газа; С-2 - пожар пролива нефти; С-3 - сгорание («пожар-вспышка») облака газовоздушной смеси (ГВС); C-4 - взрыв облака ТВС; C-5 - факельное горение газа. Основными опасными последствиями аварий являются: образование зоны загрязнения при проливах нефти, зоны загазованности при выбросе газа; образование зоны огневого и термического поражения при пожарах пролива нефти, факельном горении газа; образование зоны поражения высокотемпературными продуктами сгорания газопаровоздушной смеси (ГПВС); образование воздушной ударной волны при взрывных превращениях облаков ГПВС на открытой площадке; образование осколочного поля при разрушении оборудования, зда- 
Таблица 5.

Перечень основных возможных причин возникновения аварий

\begin{tabular}{|c|c|c|}
\hline Составляющая (участок) объекта & $\begin{array}{c}\text { Факторы, способствующие возникновению и раз- } \\
\text { витию аварий }\end{array}$ & Возможные причины аварий \\
\hline 1 & 2 & 3 \\
\hline Технологическая площадка & $\begin{array}{l}\text { 1. Обращение в технологическом процессе значи- } \\
\text { тельных количеств опасных веществ, способных } \\
\text { образовывать с воздухом } \\
\text { взрывоопасные смеси. }\end{array}$ & $\begin{array}{l}\text { 1. Отказы и неполадки технологического оборудо- } \\
\text { вания (нарушение герметичности трубопроводов, } \\
\text { отказы арматуры и разъемных соединений, разгер- } \\
\text { метизация емкостного оборудования). }\end{array}$ \\
\hline Площадка резервуаров & $\begin{array}{l}\text { 2.Содержание большого количества опасного веще- } \\
\text { ства в единичном оборудовании. }\end{array}$ & $\begin{array}{l}\text { 2. 0тказ систем контроля и систем противоаварийной } \\
\text { защиты объекта. }\end{array}$ \\
\hline
\end{tabular}

ний и сооружений.

Риск-сессия проводилась в Тюменской области, на территории на площадке промыслового объекта АО «Мессояханефтегаз» при эксплуатации ЦПС. Обзор в соответствии с техническим заданием на проведение анализа риск-сессий HAZOP проводился в отношении следующих позиций: осмотр территории ЦПС и периметра ограждения; обустройство переходов через линии технологических трубопроводов; освещение в ночное время; системы оповещения о пожаре; состояние эвакуационных путей и их маркировка; рассмотрение инструкций по безопасной эксплуатации объекта; контроль работы резервного источника электропитания; проверка системы автоматического переключения электропитания с рабочего ввода на резервный; рассмотрение сценария возможного возгорания дизельной электростанции при автоматическом включении ее в работу (при очередном испытании работоспособности электростанции).

Результаты проверки: проведен осмотр технологических линейных трубопроводов по сбору сырой нефти; рассмотрены результаты проведенных ранее рисксессий; проведен осмотр резервной электростанции; проанализировали риски возгарания при перегрузке генератора; рассмотрели возможный сценарий возгорания дизельной электростанции; запланировали мероприятие по снижению возможности возникновения возгорания на станции (установить предохраняющее устройство, исключающее автоматический пуск электростанции до устранения короткого замыкания электрических сетей внутри производственных площадей ЦПС).

По результатам проверки вырабатываются решения по повышению эффективности и надежности систем безопасности.

В результате проведения риск-сессий идентификации опасностей (HAZOP) был выявлен реальный риск возникновения аварийной ситуации в виде возгорания оборудования, включающегося в технологический процесс в автоматическом режиме, а именно риск возгорания на дизельной электростанции, при отключении центральной подачи электроэнергии. При детальном рассмотрении данного вопроса, было зафиксировано, что возгорание в подобных автоматических установках может ликвидироваться только с помощью автоматических установок газового пожаротушения. При повышении температуры или возникновения дыма, система автоматически открывает запорные клапаны установки и заполняет объем помещения инертным газом СO2, который не поддерживает горение, тем самым замещая кислород и понижая его концентрацию в помещении.

Поскольку одной из важнейших задач предприятий ТЭК на ОПО является создание безопасных и безвредных условий труда, исключающих травматизм и профессиональные заболевания, для выявления, и в дальнейшем для предотвращения, несчастных случаев на предприятии и повышения уровня организации техники безопасности на площадке промыслового объекта АО «Мессояханефтегаз» при эксплуатации ЦПС был проведен анализ по идентификации опасностей с помощью метода риск-сессий с использованием одного из методов риск-сессий идентификации опасностей и работоспособности системы - HAZOP.

Проведенный мониторинг и идентифицирование прямых и косвенных факторов, определяющих возникновение аварийных ситуаций на предприятии, с использованием риск-сессий исследования опасностей позволили сформулировать первостепенные мероприятия по повышению эффективности и надежности систем промышленной безопасности на ОПО АО «Мессояханефтегаз» и прилегающей к нему территории: выполнение технологического процесса добычи нефти и газа в соответствии с действующими правилами и инструкциями; своевременное восстановление производственного оборудования, удовлетворяющего требованиям нормативной документации и не являющегося источником травматизма и профессиональных заболеваний; использование надежно действующих и регулярно проверяемых контрольно-измерительных приборов, устройств противоаварийной защиты, средств получения и передачи информации; осуществление технических и организационных мер по предотвращению взрывов и проти- 
вопожарной защите.

Комплекс мероприятий при проведении работ по локализации и ликвидации последствий аварий в части защиты здоровья и жизни людей, включает пересмотр графика текущего ремонта техники и оборудования, имевшей простои и выходы из строя, пересмотр сметы затрат на проведение технического обслуживания техники, пересмотр стандарта инженерного обеспечения работ по локализации и ликвидации последствий аварий в части качества подготовки и рационального распределения инженерной техники, привлекаемой для обеспечения работ.

В результате проведения риск-сессий идентификации опасностей был выявлен реальный риск возникновения аварийной ситуации в виде возгорания оборудования, включающегося в технологический процесс в автоматическом режиме. Анализ данной проблемы показал, что возгорание в подобных автоматических установках можно ликвидировать только с помощью автоматических установок газового пожаротушения. В совокупности реализованные организационные и технические решения позволяют обеспечивать безопасность ведения технологического процесса, а также предотвращение и локализацию возможных аварий.

Подводя итог выше сказанному, необходимо отметить, что своевременная и качественная идентификация опасностей и оценка рисков в сфере производственной безопасности, системный подход к учету и изучению факторов, влияющих на идентификацию опасностей и оценку риска для отдельных лиц, групп населения, объектов, окружающей природной среды и т.д., позволяют обеспечить безопасные условия труда, сохранение жизни и здоровья работников.

\section{ЛИТЕРАТУРА}

1. The new paradigm of an environmentally-driven resource-saving technologies for processing of mining. / I.V. Shadrunova, 0.E. Gorlova and V.A. Zhilina. 2019 IOP Conf. Ser.: Mater. Sci. Eng. 687066048 - URL: https://doi.org/10.1088/1757-899X/687/6/066048 (date of the application 22.09.2020).

2. Application of risk-based approach in design of water supply systems / A.I. Yuhno and N.K. Plugotarenko. 2019 IOP Conf. Ser.: Mater.Sci. Eng. 687 066039 - URL: https://doi.org/10.1088/1757-899X/687/6/066039 (date of the application 22.10.2020).

3. Technosphere safety of West Siberian region and protection of human health in aspects of biogeochemical living conditions and man-made development of region / E.V. Zhilyakov, M.S. Monakhov and I.Yu. Tomus.2019 IOP Conf. Ser.: Mater.Sci. Eng. 687066033 - URL: https://doi.org/10.1088/1757-899X/687/6/066033 (date of the application 22.10.2020).

4. Егоров А.Ф. Анализ риска, оценка последствий аварий и управление безопасностью химических, нефтеперерабатывающих и нефтехимических производств / А.Ф. Егоров, Т.В. Савицкая. - Москва: КолосС, 2010. - 526 с.

5. Бедерова А.Б. Оценка и управление производственными рисками в системе обеспечения безопасности работника: специальность 08.05.01 Экономика: автореферат диссертации на соискание степени кандидата экономических наук / А.Б. Бедерова; Науч. ИИТиСС. - Москва, 2008. - 29 с.

6. Матвеевцев В.Е. Анализ причин возникновения аварийных ситуаций при эксплуатации газоиспользующих установок и стратегия совершенствования системы производственного контроля / В.Е. Матвеевцев, Кафтанов, 0.А. Манин [и др.] // Молодой ученый. — 2016. — №6. — C. 131-133.

7. Федорец А.Г. Методические подходы к оценке производственных рисков на основе анализа выполнения нормативных требований / А.Г. Федорец. // Национальная ассоциация центров охраны труда. - 2011. - № 1. - С.13-17.

8. Technogenic risk control / Yu.A. Izvekov, E.M. Gugina and V.V. Shemetova. 2018 IOP Conf. Ser.: Mater. Sci. Eng. 451 012178 - URL: https://iopscience.iop.org/ article/10.1088/1757-899X/451/1/012178 (date of the application 22.10.2020).

9. Malinetsky G.G. Modern problems of nonlinear dynamics / G.G. Malinetsky, A.B.Potapov. - Moscow: Editorial of URSS, 2000. 336 p.

10. Tabor M. Chaos and integrability in nonlinear dynamics / M.Tabor - Moscow: Editorial of URSS, 2001. 318 p.

11. Компания «Протект Бизнес Ресурс». Методика HAZOP (hazard and operability study): [сайт]. - URL: https://protect-br.ru/blog/metodika-hazop-analizopasnosti-rabotosposobnosti/ (дата обращения: 09.06.2020).

12. Научно-технический центр «Технологии и безопасности». Исследования опасности и работоспособности (HAZOP): [caйт]. - URL : http://ntc-tb.ru/services/ analiz-i-otsenka-riskov/issledovaniya-opasnosti-i-rabotosposobnosti-hazop/ (дата обращения: 09.06.2020).

13. Компания «Risk Concept». Анализ и оценка опасных производственных объектов (0П0): [сайт]. - URL: https://riskconcept.ru/analiz-i-otsenka-riskovopasnyh-proizvodstvennyh-obektov-opo/ (дата обращения: 09.06.2020).

14. Рекомендации по разработке планов локализации и ликвидации аварий на взрывопожароопасных и химически опасных производственных объектах: официальное издание: Положение о федеральном государственном надзоре в области промышленной безопасности: утверждено Постановлением Правительства РФ от 15.11.2012 №1170. 29.: введено в действие Приказом Ростехнадзора от 26.12.2012 №781. - Москва : НТЦ ЯРБ, 2012. - 32 с.

15. ГОСТ Р 12.3.047-2012. Система стандартов безопасности труда (ССБТ). Пожарная безопасность технологических процессов. Общие требования. Методы контроля. 0бщие положения: национальный стандарт Российской Федерации: издание официальное: утвержден и введен в действие Приказом Федерального агентства по техническому регулированию и метрологии от 27 декабря 2012 г. N 1971-ст: введен впервые: дата введения 2012-12-27 / разработан ФГБУ "ВНИИПО" МЧС России. - Москва: Стандартинформ, 2012. - 125 с.

16. ГОСТ12.1.007-76. Система стандартов безопасности труда. Вредные вещества. Классификация и общие требования безопасности: национальный стан- 
дарт Российской Федерации: издание официальное: утвержден и введен в действие Постановлением Государственного комитета СССР по стандартам от 10.03.76 N 579: введен впервые: дата введения 1976-03-10 / разработан Минхимпром России. - Москва : Стандартинформ, 2007. - 10 с.

17. ГОСТ1510-84. Нефть и нефтепродукты. Маркировка, упаковка, транспортирование и хранение: национальный стандарт Российской Федерации: издание официальное: утвержден и введен в действие приказом Постановлением Государственного комитета СССР по стандартам от 07.08.84 N 2776: введен впервые: дата введения 2011-07-05 / разработан Миннефтепром России. - Москва: Стандартинформ, 2011. - 29 с.

18. Алексеева В.А. Показатели безопасности условий труда: методики сбора и проблемы сравнения / В.А. Алексеева, А.Б. Каширин, В.В. Лесных [и др.] // Безопасность труда в промышленности. - 2017. - № 1. С. 53-60.

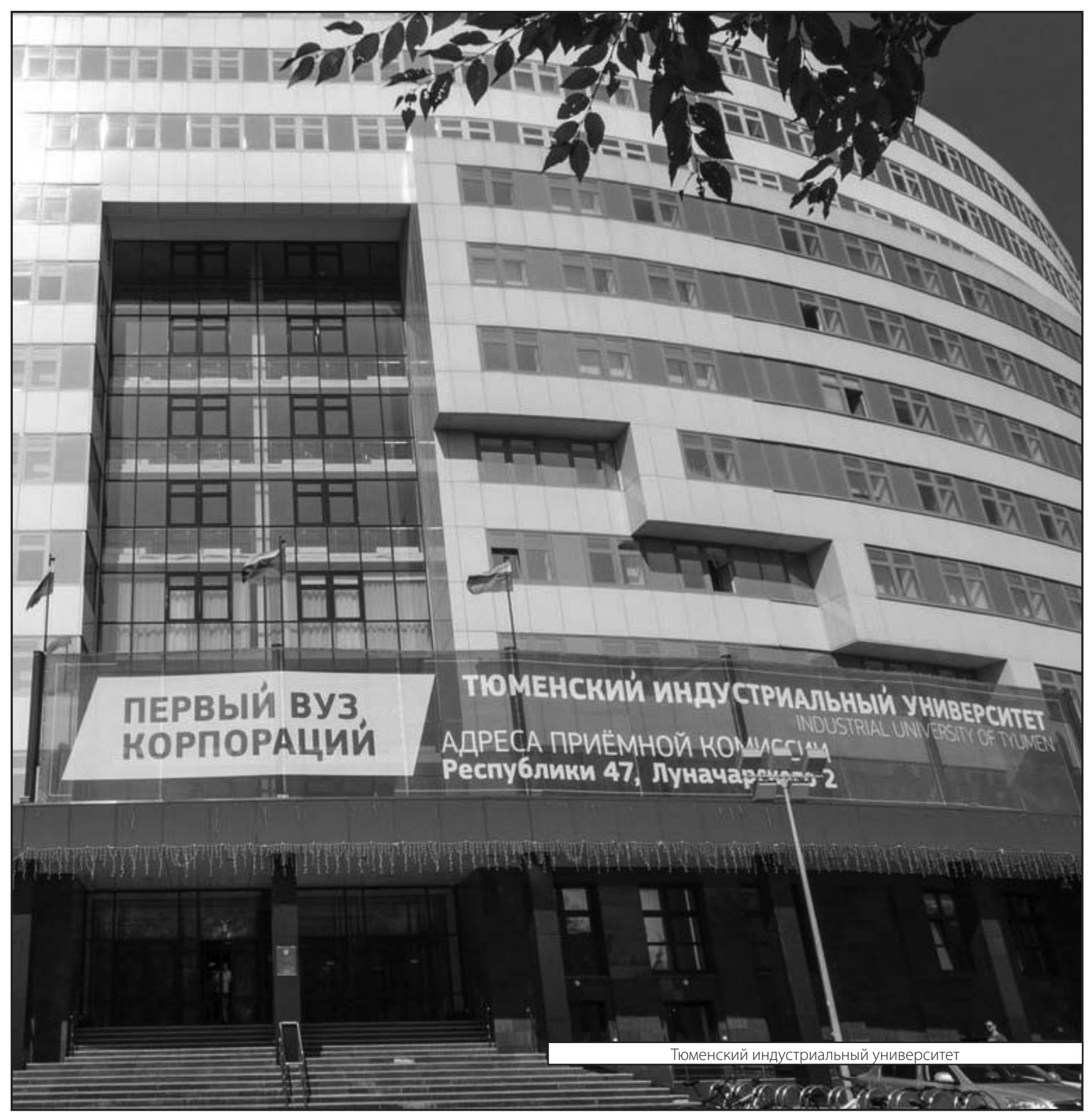

